\title{
HUBUNGAN PENGETAHUAN EVALUASI DAN SUPERVISI PENGAWAS DENGAN KINERJA EVALUASI GURU PENDIDIKAN AGAMA ISLAM (PAI) DI SD KABUPATEN TANAH DATAR
}

\author{
Romi Maimori \\ Program Studi Pendidikan Agama Islam (PAI), Jurusan Tarbiyah STAIN Batusangkar \\ Korespondensi: Jorong Buluh Kasok-Tabek, Kec. Pariangan, Kabupaten Tanah Datar \\ e-mail: maimori_qodri@yahoo.com
}

\begin{abstract}
The problem of this reseach was the lack of the teachers' knowledge and understanding about the evaluation of students' achievement. This research was descriptive research (correlation research). The population of this research was all Islamic elementary school teachers at Tanah Datar regency. They are about 319 teachers. The sample of this research was 98 teachers. The sample was selected by using stratified propotional random sampling technique that is through cohcran technique. The instrument of this research was questionnaire (Linkert scale). The evaluation of students' achievement was variable $Y$, and supervisors' supervision was variable X2. And, the teachers' knowledge of evaluation (variable X1) was analyzed by using objective test.The result of the research showed that: 1) there is any correlation between the teachers' understanding of avaluation to the teachers' achievement of evaluation of Islamic teachers at elemeantary schools at Tanah Datar regency, 2) there is any correlation between the supervisors' supervision to the teachers' achievement of evaluation of Islamic teachers at elemeantary schools at Tanah Datar regency, 3) the teachers' anderstanding and their supervision of evaluation influenced the teachers' achievement of evaluation of Islamic teachers at elemeantary schools at Tanah Datar regency.
\end{abstract}

Kata kunci: pengetahuan evaluasi, supervisi pengawas, kinerja evaluasi guru

\section{PENDAHULUAN}

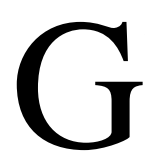
uru merupakan elemen kunci dalam sistem pendidikan karena guru Pendidikan Agama Islam (PAI) adalah guru yang mengajarkan kelompok mata pelajaran agama dan akhlak mulia dengan tujuan untuk membentuk peserta didik menjadi manusia yang beriman dan bertakwa kepada Tuhan Yang Maha Esa serta berakhlak mulia. Akhlak mulia mencakup etika, budi pekerti, atau moral sebagai perwujudan dari pendidikan agama Islam. Begitu pentingnya peran guru dalam mentransformasikan input-input pendidikan sampai akhirnya terjadi perubahan sikap dan membentuk kepribadian siswa. Untuk itu sebagai pekerja profesional seorang guru harus dapat menunjukkan usaha yang sungguhsungguh dan kinerja yang optimal dalam pelaksanaan proses pembelajaran, termasuk kinerja guru dalam melaksanakan evaluasi hasil belajar siswa, karena 
hasil belajar merupakan cer-minan dari kinerja guru.

Salah satu komponen pokok yang harus dipahami guru dalam proses pembelajaran adalah evaluasi, karena evaluasi dianggap penting dan strategis, karena hasil evaluasi berkaitan dengan kepentingan semua pihak, seperti guru, siswa, orang tua, pemerintah dan masyarakat luas. Isu-isu yang sering muncul tentang evaluasi PAI antara lain guru sering menggunakan teknik evaluasi yang monoton, evaluasi PAI dianggap identik dengan menghafal ayat-ayat pendek, sifat-sifat Allah, nama-nama Nabi. Akibatnya siswa tampak kurang semangat mengikuti pelajaran dan seringkali terlihat rasa bosan siswa, karena mereka tidak diransang untuk terlibat secara aktif dengan berbagai variasi yang seharusnya dilakukan guru agar terciptanya suasana belajar yang kondusif, dimana siswa dapat melibatkan diri secara aktif dan kreatif. (Marhamah, 2002: 7). Untuk itu Evaluasi harus dilakukan secara sistematis dan kontiniu agar dapat menggambarkan kemampuan siswa yang dinilai.

Berdasarkan kondisi objektif dilapangan kesalahan utama yang sering terjadi adalah bahwa guru PAI di SD Kabupaten Tanah Datar mengevaluasi hanya dilakukan pada saat-saat tertentu, seperti hanya pada akhir unit, pertengahan dan akhir suatu program pengajaran dan akibat yang terjadi minimnya informasi tentang para siswa sehingga menyebabkan banyaknya perlakuan prediksi guru menjadi bias, guru sering tidak siap dengan metode dan prosedur pelaksanaan evaluasi dan menganalisis hasil evaluasi dan para guru merasa bahwa analisis hasil evaluasi terlalu banyak menghabiskan waktu. Berdasarkan kondisi ini, terkesan bahwa pelaksanaan evaluasi pembelajaran oleh guru PAI di kabupaten Tanah Datar hanya sebuah rutinitas dari sebuah sistem yang harus dipenuhi meskipun tanpa memper- hatikan kaedah-kaedah evaluasi yang tepat.

Pelaksanaan tugas guru masih sangat diperlukan pembinaan karena masih banyaknya terdapat kesulitankesulitan dan kelemahan-kelemahan para guru dalam melaksanakan proses pembelajaran di sekolah. Kegiatan supervisi yang dilakukan oleh pengawas akan sangat membantu meningkatkan kemampuan profesional guru dengan segala aspeknya seperti perbaikan metode dan teknik mengajar, pengembangan kurikulum, pengadaan media pembelajaran, perbaikan cara dan prosedur penilaian. Hal ini dapat dilakukan oleh pengawas melalui kegiatan kunjungan sekolah, kunjungan kelas, pembicaraan secara individual, diskusi kelompok dan sebagainya. Dengan mempertimbangkan berbagai kelemahan yang melekat pada sistem yang ada, perlu dicarikan alternatif pemecahan supaya guru dapat meningkatkan kinerjanya sebagai pekerja yang profesional dan harkat diri secara wajar sesuai dengan akumulasi pengalaman hidup dan keahlian profesionalnya. Kegiatan yang dapat direalisasikan untuk menjamin profesionalisme guru agar senantiasa meningkatkan pengetahuan dan keterampilannya.

Di samping itu, pembinaan dan pengembangan potensi terhadap guru mutlak diperlukan oleh pihak-pihak yang diberi kewenangan yaitu pengawas pendidikan yang telah ditunjuk oleh instansi terkait, sehingga kinerja guru benar-benar dapat ditingkatkan, karena masih banyaknya terdapat kesulitankesulitan dan kelemahan-kelemahan para guru dalam melaksanakan proses pembelajaran di sekolah, permasalahan tersebut tidak hanya disebabkan oleh minimnya sarana pendidikan, tetapi juga disebabkan oleh kurang profesionalnya para guru dalam melakukan penilaian dan evaluasi pembelajaran, padahal mutu pembelajaran dan hasil dari proses 
pembelajaran yang telah dilaksanakan dapat diketahui dengan kinerja guru melakukan evaluasi pembelajaran.

Berdasarkan kondisi di atas maka penulis tertarik untuk melihat bagaimana kinerja evaluasi guru PAI di SD Kabupaten Tanah Datar dengan melihat aspek pengetahuan evaluasi guru dan aspek supervisi pengawas.

Adapun tujuan penelitian ini secara umum adalah untuk meningkatkan kinerja guru dalam melakukan evaluasi hasil belajar Pendidikan Agama Islam di SD Kabupaten Tanah Datar, sedangkan secara rinci tujuan operasional penelitian ini adalah untuk mengetahui; 1) Hubungan pengetahuan evaluasi guru dengan kinerja evaluasi guru PAI di SD Kabupaten Tanah Datar, 2) Hubungan supervisi pengawas dengan kinerja evaluasi guru PAI di SD Kabupaten Tanah Datar, 3) Hubungan pengetahuan evaluasi guru dan supervisi pengawas secara bersama-sama dengan kinerja evaluasi guru PAI di SD Kabupaten Tanah Datar.

\section{KAJIAN TEORI}

\section{Kinerja Guru}

Proses kerja selalu mempunyai langkah-langkah kerja yang senantiasa mengarah pada pencapaian hasil pekerjaan yang sesuai dengan tuntutan kerja. Apabila suatu pekerjaan dilaksanakan sesuai dengan prosedurnya, maka akan sampai kepada hasil kerja yang diinginkan, yang merupakan tuntutan pekerjaan tersebut. Tolok ukur dari kinerja adalah tuntutan pekerjaan yang mengambarkan hasil yang ingin dicapai.

Menurut Simanjuntak (2005) yang mengemukakan kinerja adalah tingkat pencapaian hasil atas pelaksanaan tugas tertentu, maka kinerja adalah keberhasilan tugas yang dicapai oleh seorang dalam melaksanakan tugas yang di- emban kepadanya, baik dilihat dari segi proses maupun dari segi hasil yang diperoleh.

Di dalam kamus besar Bahasa Indonesia (Depdiknas RI, 2003: 570546) kinerja diartikan sebagai berikut: 1) sesuatu yang dicapai, 2) prestasi yang diperlihatkan, 3) kemampuan kerja. Sedangkan, menurut Mahsun (2006), bahwa kinerja merupakan gambaran mengenai tingkat pencapaian pelaksanaan suatu kegiatan, program, kebijakan dalam mewujudkan sasaran, tujuan, misi, dan visi yang tertuang dalam perencanaan strategi organisasi.

Menurut Veithzal (2004: 309), dikatakan kinerja sebagai suatu fungsi dari motivasi dan kemampuan. Untuk menyelesaikan tugas dan pekerjaan, seseorang harus memiliki derajat kesediaan dan tingkat kemampuan tertentu. Dan menurut Hadari (2006: 63), kinerja adalah hasil dari pelaksanaan suatu pekerjaan, baik yang bersifat fisik/mental maupun non fisik/non mental.

Menurut Ondi dan Aris (2010: 22) mengemukakan indikator-indikator kinerja guru adalah; 1) Kemampuan membuat perencanaan dan persiapan mengajar, 2) Penguasaan materi yang akan diajarkan kepada siswa, 3) Penguasaan metode dan strategi mengajar, 4) Pemberian tugas-tugas kepada siswa, 5) Kemampuan mengelola kelas, 6) Kemampuan melakukan penilaian dan evaluasi. Lebih lanjut diterangkan Mulyasa (2008: 41), bahwa guru memerlukan kompetensi yang tinggi untuk melaksanakan empat tugas pokok, yaitu: 1) Merencanakan tujuan dan mengidentifikasi kompetensi yang hendak dicapai, 2) Melihat keterlibatan siswa dalam pembelajaran, bukan saja secara jasmaniah tetapi juga secara psikologis, 3) Memaknai kegiatan pembelajaran, dan 4). Melaksanakan evaluasi.

Dari beberapa definisi di atas dapat disimpulkan kinerja guru adalah hasil kerja yag ditunjukkan oleh guru dalam 
melaksanakan tugas sebagai tenaga pendidik berdasarkan kemampuan, kecakapan dan kesungguhan dalam melaksanakan tugas serta dapat mempertanggung-jawabkannya, dan Kinerja guru yang dimaksud dalam tulisan ini adalah kinerja guru dalam kegiatan evaluasi hasil belajar PAI, yaitu; 1). Kinerja guru dalam perencanaan evaluasi, 2). Kinerja guru dalam melakukan dan melaksanakan evaluasi, 3). Mengolah dan menganalisis hasil evaluasi dan 4). Menindak lanjuti hasil evaluasi.

\section{Pengetahuan Evaluasi Guru}

Dalam bahasa Inggris pengetahuan disebut knowledge dan dalam bahasa Arab 'ilm lawan dari kata jahl yang berarti ketidaktahuan. Pengetahuan ilmiah merupakan keseluruhan bentuk upaya kemanusiaan untuk mengetahui sesuatu dengan memperhatikan objek yang ditelaah dan cara yang digunakan dalam kegunaan pengetahuan tersebut (Ensiklopedi Islam, 1997: 201)

SuriaSumantri (2001: 50) menjelaskan bahwa pengetahuan diperoleh berdasarkan rasio dan logika berpikir, dari ide-ide yang menurut anggapannya jelas dan dapat diterima, ide-ide ini bukanlah ciptaan fikiran manusia tetapi sudah ada jauh sebelum manusia memikirkannya. Masalah utama yang timbul dari caraberpikir ini adalah mengenai kriteria untuk mengetahui akan kebenaran dari suatu ide yang jelas dan dapat dipercaya.

Dari pendapat di atas dapat dipahami bahwa pengetahuan adalah sesuatu yang diketahui manusia yang tersusun dalam alam logika yang didapat manusia baik dari tangkapan panca inderanya maupun melalui pengalamannya. Evaluasi secara bahasa berasal dari bahasa Inggris yaitu evaluation yang berarti penilaian atau pemeriksaan. Menurut Slameto (2001: 16) evaluasi adalah kegiatan mengumpulkan data seluas-luasnya, sedalam-dalamnya yang bersangkutan dengan kapasitas siswa, guna untuk mengetahui sebab akibat dan hasil belajar siswa yang dapat mendorong dan mengembangkan kemampuan belajar. Dari beberapa pengertian di atas dapat disimpulkan bahwa evaluasi adalah sebuah kegiatan yang dilakukan guru untuk memantau dan mengetahui perkembangan dan kemajuan belajar siswanya setelah mengikuti proses pembelajaran.

Menurut Kusaeri (2012:17), guru harus menguasai beberapa pengetahuan terkait dengan evaluasi pembelajaran, di antaranya mengetahui prosedur-prosedur evaluasi yang tepat untuk membuat keputusan pembelajaran, mengetahui teknik melakukan evaluasi dan penskorannya, mengetahui teknik menganalisis hasil evaluasi untuk dapat membuat keputusan-keputusan di bidang pendidikan, karena evaluasi itu adalah prosedur sistematis dan mencakup kegiatan mengumpulkan, menganalisis, serta menginterpretasikan informasi yang dapat digunakan untuk membuat kesimpulan tentang karakteristik siswa sehingga dapat menentukan seberapa jauh mereka mencapai tujuan pembelajaran.

\section{Supervisi Pengawas}

Menurut Supardi, dkk (2009: 227), supervisi merupakan suatu usaha untuk memberikan pertolongan atau bantuan kepada guru-guru serta staf sekolah lainnya dengan tujuan untuk memperbaiki situasi pembelajaran di sekolah, dan mempunyai implikasi yang besar bagi usaha pencapaian tujuan pendidikan itu sendiri. Subari (1994: 25) supervisi adalah bantuan dan bimbingan profesional bagi guru dalam melaksanakan tugas instruksional guna memperbaiki proses belajar mengajar dengan melakukan simulasi, koordinasi dan bimbingan secara berkesinambungan untuk meningkatan pertumbuhan jabatan guru secara individual maupun kelompok 
sehingga ada perubahan secara berarti dari kondisi tertentu kepada kondisi yang lebih baik (to help to change). Untuk itu pendidikan yang bermutu disekolah perlu adanya pengawasan yang baik sesuai dengan kaidah keilmuan.

Wilem (2007: 96), supervisi merupakan salah satu upaya untuk merangsang, mengkoordinasikan dan membimbing pertumbuhan terus menerus dari guru di sekolah secara individual dan kolektif, untuk lebih memahami dan lebih efektif dalam mewujudkan fungsi pengajaran sehingga mereka dapat menstimulir pertumbuhan dan membimbing setiap siswa terus menerus, dan mampu dan lebih mampu untuk berpartisipasi dalam masyarakat.

Dari beberapa pengertian di atas dapat disimpulkan bahwa supervisi pendidikan suatu pelayanan untuk membantu, mendorong, membimbing serta membina guru-guru agar mampu meningkatkan kemampuan dan keterampilan mereka dalam menjalankan tugas sebagai pendidik profesional. Kegiatan supervisi dilakukan oleh pejabat yang berwewenang yaitu bisa kepala sekolah dan pengawas pendidikan, dan dalam tulisan ini supervisi yang dimaksud adalah supervisi oleh pengawas sekolah.

\section{METODE PENELITIAN}

\section{Jenis Penelitian}

Penelitian ini adalah penelitian deskriptif dengan pendekatan korelasional yaitu penelitian yang menggambarkan hubungan antara satu atau beberapa variabel dengan variabel lain. Analisis yang digunakan adalah analisis deskriptif dan inferensial. Analisis deskriptif berguna untuk mendeskripsikan masing-masing variabel baik variabel bebas maupun variabel terikat. Variabel bebas (independent variable) dalam penelitian ini adalah pengetahuan evaluasi dan supervisi pengawas. Sedangkan variabel terikat (dependent variable) adalah kinerja evaluasi guru PAI.

\section{Populasi, Sampel dan Teknik Peng- ambilan Sampel}

Populasi dalam peneliltian ini adalah semua guru PAI di SD Kabupaten Tanah Datar. Penelitian ini dimulai dengan mengumpulkan data pendahuluan di kantor Kementerian Agama kabupaten Tanah Datar, berdasarkan studi pendahuluan yang sudah dilakukan diperdapat jumlah populasi sebanyak 319 orang.

Pengambilan sampel dalam penelitian ini dilakukan dengan teknik stratifiedproporsional random sampling, untuk menentukan jumlah sampel digunakan rumus Cochran;

Tabel 1. Hasil Perhitungan Sampel

\begin{tabular}{clrrrr}
\hline No & Klasifikasi Strata & $\mathbf{P}$ & $\mathbf{q}$ & no & N \\
\hline 1. & Kualifikasi Pendidikan & 0.35 & 0.65 & 87.40 & 68.82 \\
\hline 2. & Masa kerja & 0.49 & 0.51 & 96.01 & $73.85^{*}$ \\
\hline
\end{tabular}

Keterangan:

*Angka-angka ukuran sampel terpilih (jumlah sampel yang diambil ditetapkan dengan angka maksimal.
Berdasarkan tabel 1 di atas, proporsi sampel penelitian diambil melalui perhitungan: 
73.85

$=23 \%$ dari jumlah populasi

Dari data di atas diketahui bahwa jumlah sampel dalam penelitian ini adalah sebanyak sebanyak 98 orang guru-guru PAI di Sekolah Dasar kabupaten Tanah Datar.
HASIL PENELITIAN DAN PEMBAHASAN

Rangkuman Uji Signifikansi Koefisien Korelasi antara Pengetahuan Evaluasi $\left(\mathrm{X}_{1}\right)$ Supervisi Pengawas dengan Kinerja Evaluasi Guru PAI SD di kabupaten Tanah Datar (Y), dapat dilihat pada tabel berikut:

Tabel 2.

\begin{tabular}{cccc}
\hline Korelasi antara & $\begin{array}{c}\text { Koefisien } \\
\text { Korelasi(ry1) }\end{array}$ & $\begin{array}{c}\text { Koefisien } \\
\left.\text { Determinasi( } \mathbf{r}^{\mathbf{2}}\right)\end{array}$ & Nilai Sigsifikansi \\
\hline $\mathrm{X}_{1}$ dan $\mathrm{Y}$ & 0.397 & 0.158 & 0.000 \\
\hline $\mathrm{X}_{2}$ dan $\mathrm{Y}$ & 0,331 & 0,110 & 0.001 \\
\hline $\mathrm{X} 1, \mathrm{X} 2$ dan $\mathrm{Y}$ & 0.503 & 0.254 & 0,000 \\
\hline
\end{tabular}

Ket $=$ Koefisien korelasi sangat signifikan pada $\alpha=0.05$.

\section{Hubungan Pengetahuan Evaluasi Guru dengan Kinerja Evaluasi Guru}

Berdasarkan temuan dari hasil penelitian ini terdapat hubungan yang berarti antara pengetahuan evaluasi guru dengan kinerja evaluasi guru PAI di SD kabupaten Tanah Datar yaitu sebesar 0.158 (15.80\%). Faktor yang mempengaruhi kinerja guru dalam melakukan penilaian dan evaluasi hasil karena pengetahuan evaluasi merupakan hal sangat diperlukan seseorang dalam mengevaluasi hasil belajar, sebab semakin tinggi pengetahuan evaluasi yang dimiliki seorang guru, maka cenderung semakin tinggi pula hasil yang dikerjakannya, dan terlebih lagi dalam meningkatkan kualitas hasil belajar dan pendidikan. Guru merupakan faktor penentu mutu pendidikan dan keberhasilan pendidikan di sekolah. Oleh karena itu tingkat pengetahuan evaluasi guru di suatu sekolah dapat dijadikan barometer bagi mutu dan keberhasilan pendidikan di sekolah.

\section{Hubungan Supervisi Pengawas dengan Kinerja Evaluasi Guru}

Berdasarkan temuan dari hasil penelitian ini terdapat hubungan yang berarti antara supervisi pengawas dengan kinerja evaluasi guru PAI di SD kabupaten Tanah Datar yaitu sebesar 0,110 (11\%). Supervisi berkaitan dengan membina dan membantu guru dalam meningkatkan kualitas proses pembelajaran/bimbingan dan kualitas hasil belajar siswa. Menurut Marks dan Stops yang dikutip oleh Ibrahim Bafadal (1992: 41) ada lima langkah dalam melaksanakan supervisi yaitu: 1) menciptakan hubungan yang harmonis, 2) analisis kebutuhan, 3) pelaksanaan pengembangan strategi dan media, 4) penilaian, dan 5) revisi. Dengan demikian supervisor harus dapat menciptakan hubungan kemanusian yang harmonis diantara sesama guru, supervisor dituntut cermat menganalisis kebutuhan guru dan tujuan dalam menentukan teknik serta media pembinaan yang digunakan. 
Selanjutnya mengadakan penilaian untuk menentukan tingkat keberhasilan yang dicapai dalam pembinaan kinerja guru dan revisi program pembinaan sesuai dengan hasil penilaian yang telah dilakukan.

Guru dalam melaksanakan tugasnya di sekolah sangat membutuhkan orang lain untuk memecahkan masalahmasalah yang dihadapi misalnya, dalam mengevaluasi hasil belajar, merumuskan tujuan pembelajaran. Supervisi yang dilakukan oleh pengawas terhadap guru merupakan aktivitas mengubah cara kerja guru agar menjadi lebih baik. Guru yang ingin maju akan bersedia melakukan perubahan, bersedia memperbaiki atau menerima arahan dan melaksanakan apa yang disarankan oleh pengawas.

\section{Hubungan Pengetahuan Evaluasi Guru PAI dan Supervisi Pengawas terhadap Kinerja Evaluasi Guru}

Secara bersama-sama, pengetahuan evaluasi guru dan supervisi pengawas terhadap kinerja evaluasi guru PAI di SD kabupaten Tanah Datar mempunyai hubungan positif dan signifikan yaitu sebesar $0.254(25.4 \%)$. Artinya variansi tinggi rendahnya kinerja evaluasi guru ditentukan pengetahuan evaluasi guru PAI dan supervisi pengawas. Hubungan antara pengetahuan evaluasi guru dan supervisi pengawas terhadap kinerja evaluasi guru mempunyai kaitan yang sangat berarti, seorang guru yang mempunyai pengetahuan evaluasi guru yang baik tentu akan melaksanakan tugas dengan baik dan bersungguh-sungguh dengan disiplin yang tinggi. Ditambahkan pengetahuan evaluasi guru yang tinggitentu akan meningkatkan profesionalitas guru dalam melaksanakan tugas dan peranannya sebagai guru dan sebaliknya merupakan salah satu syarat penting dalam mencapai sebuah profesionalitas yang baik sehingga menciptakan guru yang berprestasi.
Dengan demikian supervisi pengawas tentu akan menentukan profesionalitas guru dalam pelaksanaan tugas dan perannya, tanpa supervisi pengawas yang baik tentu tidak akan mampu meningkatkan profesionalitas guru dalam melaksanakan tugasnya. Keterpaduan kerja sama dan berhubungan kerja sama secara timbal balik sangat bermanfaat bagi kemajuan sekolah, maka secara besama-sama pengetahuan evaluasi guru dan supervisi pengawas mempunyai hubungan dengan kinerja evaluasi guru.

Berdasarkan temuan yang berkaitan dengan pengujian hipotesis penelitian, ternyata hubungan pengetahuan evaluasi guru sangat signifikan dari supervisi pengawas. Hal ini disebabkan karena pengetahuan evaluasi guru merupakan faktor internal, walaupun supervisi pengawas faktor eksternal, guru harus tetap berusaha meningkatkan pelaksanaan tugasnya. Sebaliknya apabila pengetahuan evaluasi guru rendah dan supervisi pengawas terlaksana, bisa saja kinerja evaluasi guru tidak terlaksana dengan maksimal karena faktor internal guru sendiri yang rendah.

\section{PENUTUP}

\section{Kesimpulan}

Berdasarkan analisis data dan pembahasan, dapat diambil kesimpulan bahwa terdapat hubungan pengetahuan evaluasi dan supervisi pengawas dengan kinerja evaluasi guru PAI di SD kabupaten Tanah Datar dapat disimpulkan sebagai berikut:

1. Terdapat hubungan positif yang signifikan antara pengetahuan evaluasi dengan kinerja guru mengevaluasi hasil belajar PAI di SD kabupaten Tanah Datar yaitudengan korelasi sebesar $15.8 \%$. Ini berarti apabila semakin tinggi pengetahuan evaluasi maka akan semakin baik 
pula kinerja evaluasi guru, begitu sebaliknya. Hal ini mengisyaratkan bahwa pengetahuan evaluasi merupakan faktor penting dalam peningkatan kinerja evaluasi guru di Sekolah DasarNegeri di kabupaten Tanah Datar.

2. Terdapat hubungan positif yang signifikan antara supervisi pengawas dengan kinerja guru mengevaluasi hasil belajar di SD kabupaten Tanah Datar yaitu dengan korelasi sebesar $11 \%$. Ini berarti apabila semakin baik supervisi pengawas maka akan semakin baik pula kinerja guru mengevaluasi, begitu sebaliknya. Hal ini menunjukkan faktor supervisi pengawas penting dan perlu dilakukan secara kontiniu guna peningkatan kinerja evaluasi guru di SD kabupaten Tanah Datar.

3. Terdapat hubungan positif yang signifikan antara pengetahuan evaluasi dan supervisi pengawas secara bersama-sama terhadapkinerja guru mengevaluasi hasil belajar di SD kabupaten Tanah Datar yaitu dengan korelasi sebesar $25.4 \%$. Ini berarti apabila semakin tinggi pengetahuan evaluasi dan supervisi pengawas secara bersama-sama maka akan semakin tinggi dan meningkat pula kinerja evaluasi guru. Hal ini memperlihatkan bahwa melalui pening-

\section{DAFTAR RUJUKAN}

Cochran, Wiliam G. 1977, Sampling technique. Third Edition. New York: John Willey \& Sons.

Dewan Redaksi Ensiklopedi Islam, 1997, Ensiklopedi Islam, Jakarta: Ictiar Baru Van Hourve

Depdiknas RI. 2003, Kamus Besar Bahasa Indonesia. Jakarta: Gramedia Pustaka Utama. katan pengetahuan evaluasi dan supervisi pengawas secara sinergis dapat meningkatkan kinerja evaluasi guru Sekolah Dasar Negeri di kabupaten Tanah Datar.

\section{Saran}

Hasil penelitian diharapkan dapat menjadi salah satu referensi bagi guruguru khususnya guru-guru PAI di SD kabupaten Tanah Datar agar dapat senantiasa meningkatkan kinerjanya dalam melakukan evaluasi hasil belajarnya, agar sasaran/tujuan pelaksanaan evaluasi sebagai cerminan hasil kerja guru dalam pelaksanaan proses pembelajaran dapat dicapai, untuk itu guru agar terus meningkatkan pengetahuan, pemahamannya dan kompetensinya dalam pelaksanaan evaluasi pembelajaran, dan pengawas sekolah dalam pelaksanaan supervisi diharapkan dapat menjalin komunikasi yang baik dengan guru-guru sehingga guru akan lebih mudah menyampaikan permasalahan dalam pelaksanaan pembelajaran selanjutnya bagi peneliti lain, disarankan untuk mengkaji berbagai variabel lain yang diduga ikut mempengaruhi kinerja evaluasi guru. Dengan demikian diperoleh gambaran yang menyeluruh dan lengkap mengenai hubungan berbagai faktor terhadap kinerja evaluasi guru.

Hadari Nawawi. 2006, Evaluasi dan Manajemen Kerja. Yogyakarta: Gajah Mada Universitas Press.

KusaeriSuprananto. 2012, Pengukuran dan Penilaian Pendidikan, Yogyakarta: Graha Ilmu.

Mahsun. 2006. Studi Pengembangan Model Pendidikan Profesional Tenaga Kependidikan. Bandung: IKIP 
Marhamah. 2002, Pengembangan Model Pembelajaran Kelompok (Cooperative Learning) pada PAI Sekolah Dasar, Bandung: UPI Press

Mulyasa. 2008. Supervisi dan Etika Profesi Keguruan. Bandung: Alfabeta

Ondi Saondi dan Aris Suherman 2010. Administrasi dan Supervisi Pendidikan. Jakarta: Bumi Aksara

Peraturan Menteri Pendidikan Nasional Nomor 22 tahun 2006 tentang Standar Isi

Rivai, Veitrizal. 2004. Manajemen Sumber Daya Manusia, Jakarta: Rajawali Press.
Simanjuntak. Payaman, 2005. Manajemen dan Evaluasi Kerja Lembaga. Jakarta: FEUI

Slameto. 1998, Evaluasi Pendidikan, Jakarta: Bina Aksara.

Subari. 1994, Supervisi Pendidikan dalam Rangka Perbaikan dalam Rangka Mengajar, Jakarta: Bumi Aksara

Supardi. dkk, Profesi Keguruan Berkompetensi dan Bersertifikat, Jakarta: UIN Jakarta Press, 2009

SuriaSumantri,Jujun S, 2001, Filsafat Ilmu Sebuah Pengantar Populer, Jakarta: CV Muliasari

Willem, Mantja, 2007. Manajemen Pendidikan dan Supervisi Pengajaran. Jakarta: Erlangga. 